\title{
Priorities for silvicultural investments: Public, government, and industry perspectives
}

\author{
by Ilan Vertinsky ${ }^{1}$, Donald A. Wehrung ${ }^{2}$, and Shelby Brumelle ${ }^{3}$
}

\begin{abstract}
This paper describes the results of a survey of desired and perceived priorities for public silvicultural investments in British Columbia. The objective of the survey was to examine the extent to which non-timber benefits command the attention of the public and of managers in government and industry having responsibility for silvicultural investment. To reflect the "public view," elected representatives from local governments were surveyed. The industry sample consisted of senior foresters, while the government sample consisted of managers at both headquarters level and in the different forest regions and districts. The study revealed that non-timber benefits commanded attention in all the groups studied but, not surprisingly, the mean priority weights varied among groups. Surprisingly, however, only a few regional differences in priorities for silvicultural investments were discovered.
\end{abstract}

\section{Résumé}

Cet exposé décrit les résultats d'un sondage sur les priorités désirées et perçues au niveau des investissements publics sylvicoles en Colombie-Britannique. L'objectif de ce sondage était d'examiner jusqu'à quel point les bénéfices non-ligneux retenaient l'attention du public et des gestionnaires gouvernementaux et industriels ayant la responsabilité des investissements sylvicoles. Afin de réfléter la "vision du public", les représentants élus des gouvernements locaux ont été retenus lors du sondage. L'échantillon de l'industrie était composé de forestiers seniors, alors que l'échantillon du gouvernement était constitué de gestionnaires du centre administratif et des différentes régions et districts forestiers. L'étude a révélé que les bénéfices nonligneux ont retenu l'attention de tous les groupes étudiés mais, évidemment, le poids moyen des priorités variait selon les groupes. D'une façon surprenante, toutefois, seulement quelques différences régionales parmi les priorités d'investissements sylvicoles ont été découvertes.

\section{Introduction}

Market mechanisms are an efficient means for registering "social preferences" when they are competitive and when they reflect comprehensively all the benefit and cost dimensions associated with a particular type of investment. In the case of forest investments, markets fail to reflect the nontimber benefits derived from the forest and its management.

Through pronouncements and legislation, government reveals the objectives that guide public investments in the forest. In practice, much of the articulation of specific objectives and trade-offs is revealed through investment decisions. This study examines the extent to which non-timber benefits are reflected in the preferences of managers in industry and government and compares them to "public" preferences. These results will help determine which objectives should be considered when developing decision-making aids for silvicultural investment decisions.

\section{The Samples}

The study surveyed samples taken from three populations. For the public sample, we contacted 329 local government representatives by mail during June 1989, including 28 mayors and 301 aldermen and alderwomen. We chose mayors, aldermen, and alderwomen as representatives of the "public" because each of the cities and towns in the sparsely populated areas of some forest regions had such elected officials, as did all of the more heavily populated cities. These

\footnotetext{
${ }^{1}$ Professor and Director, Forest Economics and Policy Analysis Research Unit, University of British Columbia, Vancouver, B.C., Canada.

${ }^{2}$ Associate Dean and Professor, Faculty of Commerce and Business Administration, University of British Columbia, Vancouver, B.C., Canada. ${ }^{3}$ Professor, Faculty of Commerce and Business Administration, University of British Columbia, Vancouver, B.C., Canada.
}

representatives were chosen using a stratified sample of about 60 people from each of British Columbia's five large forest regions and a proportionately smaller sample from the sixth forest region. Eighty-six completed questionnaires were received for a response rate of $26 \%$ that ranged from $15 \%$ to $34 \%$ across the forest regions.

For the government sample, we surveyed 342 personnel at all decision-making levels in the B.C. Ministry of Forests (i.e., headquarters, region, and district) during November 1988 by means of either personal contact or mail. Ministry representatives at the headquarters level were chosen using a convenience sample that was modified to include managers from each of the Ministry's branches. Representatives at the regional and district levels were chosen using a stratified sampling technique that reflected the number of Ministry managers in the relevant geographical offices. 208 questionnaires were returned for an overall response rate of $61 \%$. Although the response rate varied somewhat across decision-making levels, it was quite high at all levels. No differences in response rates across regions or districts were noticeable. As expected, the response rate was considerably higher for managers contacted personally $(89 \%)$ than for those contacted by mail ( $49 \%)$.

The industry sample consisted of senior foresters from both headquarters and regional offices of large forestry firms and from small firms. We delivered 171 questionnaires by either personal contact or mail during February 1989. Industry representatives at the headquarters level of large firms were chosen using a convenience sample, while those at the regional level and those from small firms were chosen using stratified sampling techniques. We received 96 completed questionnaires, including those from the chief foresters of eight of the largest firms, for an overall response rate of $56 \%$. 
No regional differences in response rates were found. Again, the response rate was higher for managers contacted personally $(81 \%)$ than for those contacted by mail $(50 \%)$.

\section{The Survey Instruments}

The questionnaires focused on a list of six aggregate objectives for silvicultural investment. These objectives were: (A) generating revenue from forest activities (B) maintaining the forest as part of a healthy natural environment (C) maintaining the forest as a renewable and sustainable source of timber (D) generating development opportunities through forest investment (E) meeting political considerations (public, bureaucratic, and industry) and (F) generating employment from forest activities. Each of these aggregate objectives was broken down into three to five related sub-objectives which more fully described various aspects of the aggregate objective. The aggregate objectives and sub-objectives were used in the questionnaires to elicit priorities for public silvicultural investments (see Table 1).

Significant effort went into developing the objectives and sub-objectives included in Table 1 . This effort was required for two reasons. First, the resulting objectives would have to capture the wide range of possible attributes that both members of the general public and forestry experts consider when evaluating forest management options. Second, because of the questionnaire design these objectives would have to reflect both normative considerations that should be pursued in making silvicultural decisions and pragmatic considerations that are followed in practice.

We began this development by constructing an original set of objectives and sub-objectives that reflected many different forest-related concepts. We then had several senior Ministry personnel answer questions similar to the ones used in the final questionnaire to see if the objectives and sub-objectives were both meaningful and practical in characterizing past decisions. This was done in a round-robin session that lasted more than two hours. We modified the objectives and subobjectives as a result of this exercise, mostly by adding and deleting some sub-objectives and partially rearranging the aggregate objectives. It became clear from this exercise that to reflect how silvicultural decisions were made in practice, we had to include an objective such as (E) that dealt with meeting political considerations (public, bureaucratic, and industry). Similarly, in order to represent the interests of the many stakeholders for the forest resource, it was clear that our overall list had to include objectives that dealt with the environment, employment, industrial development, provision of wood supply, and provincial revenues without putting undue emphasis on any one of them.

The survey used for managers from the Ministry differed in one important aspect from the one employed for the industry and public representatives. We asked the participants from the Ministry to provide priority weights on the objectives and subobjectives that reflected the current practices of the Ministry, whereas we asked the participating mayors, aldermen, alderwomen and the senior foresters from industry to indicate the priority weights that should guide Ministry decisions.

More specifically, the instructions given to the Ministry were as follows:

"Table 1 on the last page of this survey presents a list of some important objectives for forest investments to
Table 1. Objectives and Sub-objectives for Silvicultural Investments

A. Generate revenue to Province from forest activities.

Al. Provide revenues from harvesting the forest through stumpage fees, royalties, etc. paid by private forest firms.

A2. Provide revenues from other forest activities (e.g., recreation, range, wildlife, income taxes on employment and business profits, etc.).

A3. Provide Federal transfer payments to the Province for forest activities such as reforestation.

A4. Provide adequate financial return on investment from forest activities.

B. Maintain forest as part of a healthy natural environment

B1. Maintain ecological balance (watershed, soil preservation, natural habitat for fish and wildlife, etc.).

B2. Provide adequate levels of accessible non-timber forest resources (fish, game, recreational land, etc.).

B3. Provide scenic beauty.

C. Maintain forest as a renewable and sustainable source of timber

C1. Provide stable levels of economic wood supply for the existing forest product industry.

C2. Expand the wood supply to accommodate future forest firms and users of the forest.

C3. Enhance the quality of the wood supply.

D. Generate development opportunities through forest investment

D1. Encourage private investment in forest industry to expand its scope and enhance its productivity.

D2. Encourage regional development by providing infrastructure for forest activities (road construction, port construction, etc.)

D3. Provide economic base for communities solely dependent on forest industry.

D4. Develop new sources of desirable wood fibres.

E. Meet public, bureaucratic and industry political considerations

E1. Maintain public investment in forests at levels acceptable to the public.

E2. Give special consideration to influential stakeholder groups in allocating public expenditures on forest activities.

E3. Avoid conflicts among governmental levels, departments and agencies.

E4. Maintain acceptable working relationship with forest industry.

E5. Maintain equity across all stakeholder groups in allocating public expenditures on forest activities.

F. Generate employment from forest activities.

F1. Maintain/create permanent employment opportunities in private sector of forest industry.

F2. Maintain/create temporary employment opportunities in private sector of forest industry.

F3. Maintain/create temporary employment opportunities in public sector of forest industry to relieve severe unemployment.

meet. The list in Table 1 is divided into six major objectives, labelled A through F, each of which includes several sub-objectives. Please read through the objectives on this list to familiarize yourself with them. Then answer the following questions. Consider silvicultural decisions that are made at your decisionmaking level in the Ministry of Forests. What objectives are used to evaluate alternative options for silvicultural decisions at your level?

Answer this question by first considering each of the major headings in Table 1 one-at-a-time. For each major heading, allocate 100 points among the 3-5 subobjectives that are listed to reflect your belief regarding their relative importance. Record your responses in Table 2. When you have finished with one major heading go on to the next one until all six have been considered in turn. Next consider the six major 
headings relative to one another. Allocate 100 points among the six major headings to reflect your belief regarding their relative importance. Record your responses at the bottom of Table 2."

The instructions for the participants from the public and from industry differed only in the replacement of the above italicized passage with the italicized passage below:

"Consider silvicultural decisions that are made by the Provincial Ministry of Forests. What objectives do you believe should be used to evaluate alternative options for silvicultural decisions in the Ministry?"'

Thus the comparison of priorities in this paper is between the views of public representatives and industry managers regarding what is desirable and the perceptions of managers in the Ministry regarding what priorities Ministry decisions currently reflect in practice.

A pilot test was conducted to identify any methodological problems with the format of the questionnaire (e.g., problems of comprehension and sequencing biases). No such problems were discovered.

Once the data had been collected, we closely examined the responses to see whether the respondents understood the objectives that we had included. We found that all of the government, industry, and public participants who returned the questionnaire gave complete responses for the priority weights on both the aggregate objectives and sub-objectives. Unfortunately, we do not have a direct measure of non-response bias, so we cannot be sure that some subjects did not return the questionnaire because they found that the objectives and subobjectives used did not adequately reflect the priorities that they valued regarding forest management decisions.

We conclude that although the objectives and subobjectives used in the questionnaire do not necessarily capture all relevant considerations for all participants, the vast majority of participants seemed to understand the items used and they were able to provide priority weights based on them.

\section{Results-Methodology}

To examine whether the subjects contacted by mail differed in their responses from those contacted in person, we examined each of the responses using standard statistical procedures. Significant differences between the "mail contact" subjects and the "personal contact" subjects were found for fewer than $5 \%$ of the variables considered, a result consistent with a "chance" effect. We concluded that these two groups were indistinguishable in their responses. As a result, we have combined the "mail contact" respondents and the "personal contact" respondents in all of the subsequent analyses discussed in this paper.

Analysis of variance was used to establish whether there were significant differences in the mean responses of different groups of respondents on the priority weights. This approach was used to compare the priority weights across the public, government, and industry samples as well as across regional or decision-making levels within the samples.

\section{Results-Priorities on Silvicultural Objectives \\ Public Priorities on Silvicultural Objectives}

Our sample of public representatives gave the highest average priority weight to maintaining the forest as a

Table 2. Relative importance of objectives for silvicultural decisions within Ministry of Forests

\section{Allocation within Major Headings} Generate revenue to Province
from forest activities

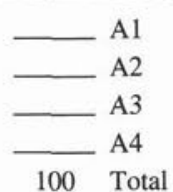

Maintain forest as a renewable and sustainable source of timber

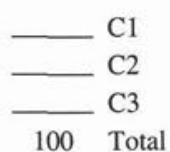

Meet public, bureaucratic, and industry political considerations

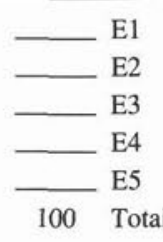

Allocation across Major Headings

E1

$\mathrm{E} 4$
Maintain forest as part of a healthy natural environment B1 B2 B3

100 Total

Generate development opportunities through forest investment

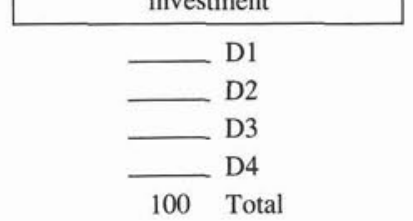

Generate employment from forest activities

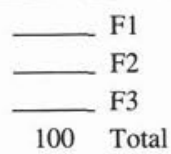
F1 F3

00 Total

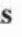
.

revenue to Province from forest activitie

- A. Generate revenue to Province from forest activities

B. Maintain forest as part of a healthy natural environment

C. Maintain forest as a renewable and sustainable source of timber

D. Generate development opportunities through forest investment

E. Meet public, bureaucratic, and industry political considerations

F. Generate employment from forest activities

100 Total

renewable and sustainable source of timber $(25.9 \%$ of the 100 priority points allocated). Maintaining the forest as part of a healthy environment ranked a close second (23.2\%). Generating revenues to the Province from forest activities and generating employment from these activities were seen as significant but less important objectives $(17.2 \%$ and $15.1 \%$, respectively). Generating development opportunities through forest investments and meeting political considerations were viewed as much less important $(10.6 \%$ and $7.9 \%$, respectively). Dispersion of individual priority ratings was approximately the same for each of the objectives after they were normalized by the objectives' average priority weight.

The regional distribution of priority weights revealed statistically significant differences only with respect to the aggregate objective of maintaining the forest as part of a healthy environment. The weight given to this objective varied from $30.1 \%$ in the Nelson region to $15.3 \%$ in the Prince George region. The maintenance of the forest as a renewable and sustainable source of timber was important in all regions, but ranked distinctly as a first priority in the Prince George and Kamloops regions. In the Vancouver and Nelson regions this objective was given second priority behind maintaining the forest as part of a healthy 
environment, while in the Prince Rupert region these two objectives tied for first priority. In the Cariboo region, generating provincial revenue tied for top priority with maintaining the forest as a renewable and sustainable source of timber, with priority for a healthy environment as a distant third.

After further aggregating the public sample into larger geographical regions, we found that development opportunities were given significantly higher average priority in the northern Interior $(13.8 \%)$ than on the Coast $(8.0 \%)$ or in the southern Interior (10.4\%). Generally, concern for sustainable wood supply was higher than environmental concerns in the Interior as compared to the Coast.

\section{Comparisons of Public, Government, and Industry Priorities}

Comparison of the average priority weights given by the public, government, and industry representatives revealed some similarities and some significant differences among the groups (Table 3 ). The three groups put approximately the same priority on generating revenue to the Province and employment from forest activities, and there were only small differences in the priorities placed on generating development opportunities through forest investment. Compared with government and industry personnel, the public representatives placed more weight (averaging about $5 \%$ ) upon maintaining a healthy natural environment and less weight (also averaging about $5 \%$ ) on maintaining the forest as a renewable and sustainable source of timber. Thus, while all three groups gave the highest average priority to maintaining the forest as a renewable and sustainable source of timber, the government and industry groups placed this objective far ahead of the environmental benefits of the forest in contrast to the public representatives who made maintaining a healthy environment a close second priority. Table 3 also shows that government personnel placed somewhat higher emphasis (averaging about $4 \%$ ) on the political considerations that forest investments involve than did the public or industry representatives.

The priority weights of the public sample were compared with the limited sample of Ministry participants who were at the most senior policy-making level. This comparison revealed that the most senior Ministry officials accurately reflected the "public view" in that their average priority weights were almost identical to the average ratings obtained from the public sample for all objectives except meeting political considerations (where the senior Ministry officials gave twice the priority that the public did). Although the small sample of senior Ministry officials limited the statistical generalizability of the result, this finding suggests that despite delegation of authority to the bureaucracy, macro-policies do reflect quite sensitively the views of the public, at least as these views would be articulated by the "average" local representative. It also suggests that the articulation of values in constructing an evaluation model for silvicultural investments could focus on the "policy level" personnel if a more sensitive reflection of public opinion in the objectives guiding Ministry decision making was desired.

In addition, the priority weights of the industry sample were compared with the subsample of chief foresters. Both the chief foresters and the other industry participants wanted the Ministry to use approximately the same priority weights in its decisions. When they did differ, the chief foresters
Table 3. Average priority weights on silvicultural objectives by sample group (standard deviations in parentheses)

\begin{tabular}{lccc}
\hline Objective & Public & Government & Industry \\
\hline $\begin{array}{l}\text { Generate revenue } \\
\begin{array}{l}\text { Maintain healthy } \\
\text { environment }(* *)\end{array}\end{array}$ & 17.2 & 15.9 & 15.7 \\
$\begin{array}{c}\text { Maintain forest as a } \\
\quad \text { renewable source of }\end{array}$ & 23.2 & 18.5 & 17.9 \\
$\quad$ timber (*) & 25.9 & 30.7 & 31.6 \\
$\begin{array}{l}\text { Generate development } \\
\text { opportunities (**) }\end{array}$ & 10.6 & 9.3 & 12.1 \\
$\begin{array}{l}\text { Meet political } \\
\text { considerations (**) }\end{array}$ & 7.9 & 11.8 & 7.1 \\
Generate employment & 15.1 & 13.8 & 15.8 \\
\hline
\end{tabular}

* Statistically different at $P<0.05$ (two-tailed test).

**Statistically different at $P<0.01$ (two-tailed test).

wanted the Ministry to put more weight on maintaining the forest as a renewable and sustainable source of timber and less weight on generating employment than did the other industry participants.

For two of the objectives we found systematic differences depending upon the location of the industry participants. Compared with managers headquartered in Vancouver or at Island/Coast regional offices, managers at regional offices in the Interior (either northern or southern) believed the Ministry should put less priority on generating revenue to the Province and more priority on generating employment. Thus there was a very clear split among industry participants on these priorities.

\section{Results-Priorities on Silvicultural Sub-objectives Public Priorities on Silvicultural Sub-objectives}

So far we have focused on the six aggregate objectives. Each of these objectives was further decomposed into three to five sub-objectives as described in Table 1. For example, aggregate objective $\mathrm{C}$ ("to maintain the forest as part of a renewable and sustainable source of timber"') was decomposed into three sub-objectives as follows:

C1. Provide stable levels of economic wood supply for the existing forest product industry.

C2. Expand the wood supply to accommodate future industrial entrants and users of the forest.

C3. Enhance the quality of the wood supply.

The respondents were asked to provide priority weights for the sub-objectives within an aggregate objective by assigning non-negative numbers to each sub-objective so that they summed to 100 .

The weights assigned within an aggregate objective could not be used directly for comparison with weights assigned to sub-objectives in other aggregate objective categories because they did not reflect the overall priority given to the aggregate objective. Therefore, the weights assigned to the sub-objectives within an aggregate objective were first normalized for each individual respondent by the weight given to the aggregate objective.

Table 4 provides the average priority weights of the public participants for specific sub-objectives. Maintaining ecological balance (watershed, soil preservation, habitat) and providing stable levels of economic wood supply for existing forest firms were seen as the most important benefit 
Table 4. Average priority weights on silvicultural sub-objectives for public, government, and industry samples

\begin{tabular}{|c|c|c|c|}
\hline Sub-objective & Public & Government & Industry \\
\hline Provide revenues from harvesting & 6.8 & 6.6 & 5.5 \\
\hline Provide revenues from other forest activities & 3.1 & 3.0 & 3.0 \\
\hline Provide Federal transfer payments $(* *)$ & 3.4 & 1.9 & 1.8 \\
\hline Provide adequate financial return on investment & 4.0 & 4.4 & 5.5 \\
\hline Maintain ecological balance & 12.5 & 10.8 & 9.9 \\
\hline $\begin{array}{l}\text { Provide adequate levels of accessible non-timber } \\
\text { forest resources }\end{array}$ & 6.0 & 5.0 & 5.2 \\
\hline Provide scenic beauty $(* *)$ & 4.6 & 2.8 & 2.7 \\
\hline Provide stable levels of economic wood supply $(* *)$ & 11.8 & 17.2 & 16.8 \\
\hline Expand the wood supply & 6.6 & 6.7 & 7.9 \\
\hline Enhance quality of the wood supply & 7.6 & 6.7 & 6.9 \\
\hline Encourage private investment $(* *)$ & 3.3 & 2.7 & 5.0 \\
\hline Encourage regional development & 2.1 & 1.7 & 2.2 \\
\hline Provide economic base for communities & 2.7 & 3.2 & 2.8 \\
\hline Develop new sources of desirable wood fibres $(* *)$ & 2.5 & 1.7 & 2.1 \\
\hline Maintain public investment $(* *)$ & 1.9 & 3.4 & 2.1 \\
\hline $\begin{array}{l}\text { Give special consideration to influential stakeholder } \\
\text { groups }(* *)\end{array}$ & 0.5 & 1.2 & 0.5 \\
\hline Avoid conflicts among governmental levels $(* *)$ & 1.8 & 2.2 & 1.0 \\
\hline Maintain acceptable working relationship with & & & \\
\hline forest industry $(* *)$ & 1.9 & 2.9 & 2.1 \\
\hline Maintain equity across stakeholder groups $(*)$ & 1.8 & 2.1 & 1.4 \\
\hline $\begin{array}{l}\text { Maintain/create permanent employment } \\
\text { opportunities in private sector }(* *)\end{array}$ & 8.7 & 7.0 & 10.0 \\
\hline Maintain/create temporary employment & & & \\
\hline $\begin{array}{l}\text { opportunities in private sector }(* *) \\
\text { Maintain/create temporary employment }\end{array}$ & 3.0 & 4.2 & 3.3 \\
\hline $\begin{array}{l}\text { Maintain/create temporary employment } \\
\text { opportunities in public sector }\end{array}$ & 3.4 & 2.6 & 2.5 \\
\hline
\end{tabular}

*Statistically different at $P<0.05$ (two-tailed test).

$* *$ Statistically different at $P<0.01$ (two-tailed test).

dimensions, accounting for almost $25 \%$ of the priority weights. Other high-priority sub-objectives that received more than $5 \%$ of the total priority points included maintaining and creating permanent employment in the private sector of the forest industry $(8.7 \%)$, enhancing the quality of the wood supply $(7.6 \%)$, providing revenues to the Province through stumpage fees $(6.8 \%)$, expanding the wood supply to accomodate future forest firms and users of the forest (6.6\%), and providing accessible non-timber forest resources (fish, game, recreational land, etc.) $(6.0 \%)$. None of the subobjectives related to meeting political considerations received more than $2 \%$ of the average priority weights.

Significant regional differences in average priority weights were found for only two sub-objectives. Providing adequate financial return on investment from forest activities received significantly higher priority among public representatives in the Cariboo region (10.6\%) than in the other regions, where the highest average priority was under $4.0 \%$. Public representatives in the Prince George and Cariboo regions gave significantly lower priority to maintaining ecological balance (6.5\% and $8.0 \%$, respectively) than did representatives in the other regions (e.g., Nelson, $17.2 \%$; Prince Rupert, $15.6 \%$; and Vancouver, $14.9 \%$ ). Comparison of priority weights for participants from the coastal and Interior regions revealed no important differences.

\section{Comparisons of Public, Government and Industry Priorities}

Table 4 provides the average priority weights for the subobjectives given by the public, government, and industry participants. For many of the sub-objectives for which all three groups gave the highest priorities, there were no differences. These sub-objectives included maintaining ecological balance, expanding the wood supply, enhancing the quality of the wood supply, providing revenues to the Province from harvesting, providing adequate levels of accessible non-timber forest resources, and providing adequate financial return on investment.

For other sub-objectives there were important differences. Providing a stable economic wood supply for existing forest companies was viewed as a significantly less important factor in silvicultural investment by public representatives (11.8\%) than by government $(17.2 \%)$ or industry $(16.8 \%)$. The benefits of creating permanent employment opportunities in the private sector of the forest industry were significantly more important to industry (10.0\%) than to the government $(7.0 \%)$ or the public $(8.7 \%)$. The benefits of providing scenic beauty were valued more significantly by the public representatives $(4.6 \%)$ than by industry $(2.7 \%)$ or government $(2.8 \%)$. Industry representatives put more priority $(5.0 \%)$ on encouraging private investment in the forest industry than did government $(2.7 \%)$ or public $(3.3 \%)$ representatives.

We also examined the relative share that different subobjectives contributed to the overall priority weight given to the two most important aggregate objectives (the forest as a source of timber and the forest as part of a healthy natural environment). Fifty-five percent of the priority weight given by the public to the forest as a source of timber was allocated to "future oriented sub-objectives," i.e., sub-objectives associated with new opportunities to expand the wood supply and enhance its quality. The government and industry 
participants allocated less weight to these future oriented subobjectives ( $44 \%$ and $47 \%$, respectively), putting more emphasis on protecting the existing wood supply.

Maintaining an ecological balance was the dominant environmental sub-objective, commanding $54 \%$ of the priority weight given by the public representatives to maintaining the forest as part of a healthy natural environment, $58 \%$ of the weight given by government, and $56 \%$ by industry. Providing adequate levels of accessible non-timber forest resources commanded $26 \%$ of the priority weight given to the aggregate environmental objective by the public, $27 \%$ by government, and $29 \%$ by industry. Concern with scenic beauty commanded $20 \%$ of the priority weight given to the aggregate environmental objective by the public, but only $15 \%$ of the weights given by government and industry.

Overall, the following sub-objectives were the most important to all three groups:

- providing stable levels of economic wood supply

- maintaining ecological balance

- maintaining/creating permanent employment in the private sector

- enhancing the quality of the wood supply

- providing revenues from harvesting to the Province

- expanding the wood supply

- providing accessible non-timber forest resources

- providing adequate financial return on silvicultural investments.

These eight sub-objectives cumulatively represent $64.0 \%$ of the average priority weights of public representatives, $64.4 \%$ for government participants, and $67.7 \%$ for industry participants. The enhancement of scenic beauty and the benefits of temporary employment in the public sector were among the top ten sub-objectives of the public representatives, but they were not among the top priorities of the other groups.

\section{Discussion and Conclusions}

Concern with biomass production has dominated traditional approaches to silvicultural decision making in Canada. Maximizing the long-run yield of the forest in physical terms has been the primary objective of traditional forest management. The objective has been pursued by providing an even flow of harvested timber in a way that would maximize the sustainable level of the flow. This desire for sustained constant volumes of timber reflects a concern for regional economic stability. In the context of this objective, silvicultural investment can increase the productive capacity of stands and correct for age-structure deficiencies and for the consequences of losses resulting from fires, pests, and past harvesting practices.

More recently, the traditional focus on biomass production has shifted to concern for the stability of economic wood supply. Concern with the long-term economics of wood supply has led to the recognition that quality and value, not only biomass, can be influenced by silvicultural practices. Silvicultural investments permit tighter control over the future characteristics of the resource.

The recognition that investment in the forest must contribute to the maintenance of the forest as a renewable and sustainable source of timber appears to be prevalent in our sample. It was rated as the highest priority for silvicultural investment by all three groups in our study. The emphasis, however, was on the protection of the existing industry rather than on the creation of new opportunities through expansion of the wood supply or the enhancement of its quality.
While the introduction of the financial/economic dimension into the theory and practice of silvicultural investment decisions is an important step toward comprehensive forest management, it ignores important benefits and costs associated with a broader social perspective of forest management. The stand-oriented investment decision framework ignores the multiple uses of the forest resource and thus undervalues the benefits of investment in them.

Our survey shows that while the concern for economic wood supply dominated other evaluation dimensions in silvicultural investment decisions, the non-timber values of the forest were almost equally important. The maintenance of an ecological balance was dominant among the environmental sub-objectives. The provision of adequate levels of accessible non-timber resources (e.g., fish and game) and concern with scenic beauty were important secondary objectives.

Given the importance of forest resource to the economy and the fact that public ownership is dominant (95\% in British Columbia), one must consider the uses of silvicultural investment as an instrument of government fiscal policy. Ownership of the resource provides the government with the opportunity to raise revenues, thus reducing the need to tax the population directly. Exacting the true "rent" from the resource is also a means of ensuring efficient use of the resource. In our survey, the revenue objective commanded a high weight by all groups, but it was clearly outweighed by the long-term objectives of maintaining wood supply and maintaining the forest as part of a healthy natural environment.

Forest investment can also serve as a social policy instrument. It can serve as a tool for generating employment and development opportunities as well as meeting other political considerations. The combined priority weights placed upon "fiscal and social policy"' benefits of the investment activity were surprisingly high and similar in the three groups. The preference for "types" of social policies for which investment in the forest is used varied among the groups, though employment generation was dominant in the average priority ratings of all groups.

A significantly greater percentage of the government (61\%) and industry $(56 \%)$ representatives solicited for this study agreed to participate than the public representatives $(26 \%)$ contacted. Part of this discrepancy was due to the fact that the public was solicited only by mail, whereas we contacted the government and industry samples partially by mail and partially by personal contact. Even when we restrict attention to those people contacted by mail, government and industry representatives participated at about twice the response rate of public representatives. A response rate of $26 \%$ is somewhat above normal for a typical public survey of the length that we used. We feel that the mayors, aldermen, and alderwomen who served as public representatives in our study were quite interested in the topics addressed by the survey, and this was the reason for the above-normal response rate for this group. For the managers from the Ministry of Forests who formed our government sample and for the senior managers from the forest industry, we feel the extraordinarily high response rate to a mail survey was primarily due to the fact that their livelihood is integrally concerned with the management of the forest resource.

Eight of the 22 sub-objectives that we considered in this study captured almost two-thirds of the priority assigned by each of the three stakeholder groups surveyed. One consequence of this result is that an evaluation model for 
silvicultural investment can be developed that is based on relatively few indicators. Additional analysis of the priority weights suggests that the sub-objectives can be combined into four principal dimensions that include (1) maintaining the forest as part of a healthy natural environment (2) investing in the forestry (both dollars and permanent employment) and providing stable levels of economic wood supply for the existing forest product industry (3) enhancing the quality and quantity of the wood supply and (4) generating temporary employment (both in the private and public sectors). The results of this analysis reinforce our belief that the public, government, and industry all understand the importance of pursuing multiple, conflicting objectives in managing the forest resource.

This study focused upon perceived priorities. Priorities are important in the sense that they provide a measure of the degree of attention that is paid or should be paid to specific objectives and sub-objectives. However, policy should be guided by consideration of costs and benefits, not only by the strength of concern.

\section{Acknowledgement}

The authors are grateful to the British Columbia Ministry of Forests for funding this study. This paper was reviewed and approved for publication by the B.C. Ministry of Forests. The approval, however, does not constitute endorsement or agreement with the contents of this paper. The opinions are solely those of the authors, who bear responsibility for any errors. We especially would like to acknowledge the stimulating comments received from D. Booth, T. Niemann, W.T. Stanbury, and an anonymous referee.

\section{$\underline{\text { CIF/IFC Corporate Sustaining Members }}$}

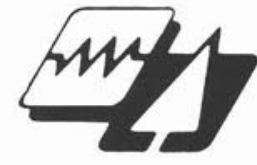

Department of

Energy and Forestry

Prince Edward Island
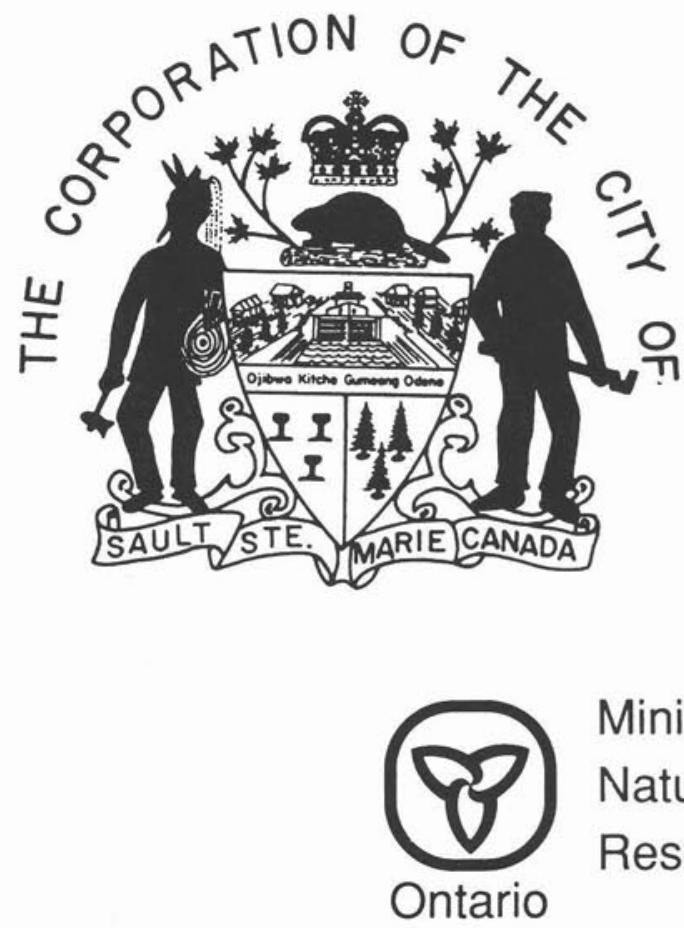

Ministry of Ministère des

Natural

Richesses

Resources naturelles 